Technical note

\title{
Stability of polycyclic aromatic compounds in polyurethane foam-type passive air samplers upon $\mathrm{O}_{3}$ exposure
}

\author{
Narumol Jariyasopit ${ }^{\text {a }}$, Yongchun Liu ${ }^{\mathrm{b}}$, John Liggio ${ }^{\mathrm{a}}$, Tom Harner ${ }^{\mathrm{a},{ }^{*}}$ \\ a Air Quality Processes Research Section, Environment Canada, Toronto, Ontario, M3H 5T4 Canada \\ b State Key Joint Laboratory of Environment Simulation and Pollution Control, Research Center for Eco-Environmental Sciences, \\ Chinese Academy of Sciences, Beijing, 100085, China
}

\section{H I G H L I G H T S}

- Stability of polycyclic aromatic compounds (PACs) on PUF disks is evaluated.

- Flow tube chamber was used to simulate 2 months exposure to $\mathrm{O}_{3}$.

- Some degradation of PAHs occurred under low relative humidity (RH).

- The majority of the PACs were stable upon $\mathrm{O}_{3}$ exposure at $50 \% \mathrm{RH}$.

- PUF disk sampler is validated for measuring PACs in air under typical conditions.

\section{A R T I C L E I N F O}

\section{Article history:}

Received 8 May 2015

Received in revised form

25 August 2015

Accepted 27 August 2015

Available online 2 September 2015

\section{Keywords:}

Passive air sampling

PUF disk

PACs

Alkylated PACs

Ozone exposure

Flow tube chamber

\begin{abstract}
A B S T R A C T
Stability of polycyclic aromatic compounds (PACs) in polyurethane foam (PUF) disks upon $\mathrm{O}_{3}$ exposure was studied in a flow tube. A wide range of PACs was evaluated by spiking PUF disks with PACs and exposing to $\mathrm{O}_{3}$ at concentrations that were equivalent to two months exposure, a typical deployment period for these passive air samplers. Ambient concentrations of $\mathrm{O}_{3}(\sim 50 \mathrm{ppb})$ at $0 \%$ and $50 \%$ relative humidity (RH) were applied. At $0 \% \mathrm{RH}, 23$ of 68 PACs yielded more than $50 \%$ loss after exposure. The mean percent loss was $30 \%$ with perylene and 9,10-dimethylanthracene the most reactive polycyclic aromatic hydrocarbons (PAHs) and alkylated PAHs, respectively. At $50 \% \mathrm{RH}, 77 \%$ of the studied PACs was stable upon $\mathrm{O}_{3}$ exposure ( $\mathrm{PAC}_{\text {exposed }} / \mathrm{PAC}_{\text {unexposed }}>0.7$ ). The mean percent loss was $17 \%$ and only 7 of 68 PACs yielded greater than $50 \%$ loss. In general, the reactivity of most of the PACs decreased at higher $\mathrm{RH}$, except for the reactive PAHs (acenaphthylene, 2,3-dimethylanthracene, 9,10-dimethylanthracene, dibenzothiophene, and 2-methyldibenzothiophene) which demonstrated lower RH dependence. The experimental conditions in this study represent a worst case scenario for the stability of PACs sorbed to PUF. In reality, the sampling of PACs in ambient air represents an 'aged' component of PACs where the most reactive species have already partially been removed. Also, PACs in ambient air will be associated with the particle phase to varying extents that will help to enhance their stability. Therefore, under regular operating conditions, over a 2-month exposure, we expect a minimal error in the measurement of total concentration of PACs in air using the PUF disk passive sampler.
\end{abstract}

Crown Copyright $\odot 2015$ Published by Elsevier Ltd. All rights reserved.

\section{Introduction}

Passive air sampling has been widely used in air monitoring for persistent organic pollutants (POPs) (Bartkow et al., 2004; Harner et al., 2006; Jaward et al., 2004; Schuster et al., 2015) as it is convenient, inexpensive, and does not require electricity to operate.

\footnotetext{
* Corresponding author.

E-mail address: tom.harner@ec.gc.ca (T. Harner).
}

Chemicals, both gas-phase and particulate-phase, are passively accumulated in sampling media being deployed for months at a time. The sampling media include semipermeable membrane devices (SPMDs), polyurethane foam (PUF) disks, and XAD resin. Given that they are easy to handle, polyurethane foam (PUFs) disks are commonly used in a number of air monitoring programs, (Jaward et al., 2004; Klánová et al., 2006; Motelay-Massei et al., 2005; Pozo et al., 2004; Schuster et al., 2015) including the Joint Canada/Alberta Implementation Plan on oil sands Monitoring 
(JOSM) by Environment Canada and Alberta Environment and Sustainable Resource Development.

Under JOSM, the passive sampling monitoring network was initiated to measure polycyclic aromatic compounds (PACs) across the oil sands region. The PACs being monitored include parent polycyclic aromatic hydrocarbons (PAHs), alkylated PAHs (alkPAHs), dibenzothiophene (DBT) and alkylated DBTs. (Schuster et al., 2015) Released from pyrogenic (e.g. combustion processes) and petrogenic (e.g. bitumen and upgrading activities) sources, these compounds are ubiquitous and potentially carcinogenic and mutagenic. (Baird et al., 2005) Compared to pyrogenic sources, chemical composition of bitumen is relatively enriched with alkPACs, DBT, and alk-DBTs, (Hawthorne et al., 2006; Yang et al., 2011) therefore, they are used as an indicator of petrogenic sources.

A concern regarding the passive sampling method is the potential reactions of PACs with atmospheric oxidants such as $\mathrm{OH}$ radicals, $\mathrm{NO}_{3}$ radicals, $\mathrm{N}_{2} \mathrm{O}_{5}$, nitrogen oxides, and $\mathrm{O}_{3}$ during field deployment. This raises a question of whether or not they are capable of accurately reflecting contaminant concentrations in air. Long deployment periods may allow chemicals trapped in the sampling media to undergo transformation reactions with oxidants, which can alter the relative abundances of PACs in air. For example, field observations have found that particulate-bound $\mathrm{PAH}$ concentrations measured using conventional high volume active air samplers could be underestimated by up to $100 \%$ or more, compared to the concentrations measured by denuders. (Goriaux et al., 2006; Schauer et al., 2003) However, limited data exist for the stability of PACs associated with passive sampling substrates. Bartkow et al. reported the photodegradation of PAHs in SPMDs that were not protected from sunlight. (Bartkow et al., 2006) There are several studies investigating heterogeneous reactions of surface-bound PAHs with gaseous oxidants using various substrates including silica, graphite, soot particles, particulate matter, and glass fiber filters. (Bedjanian and Nguyen, 2010; Esteve et al., 2004; Jariyasopit et al., 2014; Nguyen et al., 2009; Perraudin et al., 2007; Pöschl et al., 2001; Ringuet et al., 2012) The results from previous studies suggest that $\mathrm{O}_{3}$ was an effective oxidant for degrading surface-bound PAHs (Jariyasopit et al., 2014; Pitts et al., 1986). As a result, for passive sampling methods where PUFs are protected from direct sunlight, wet precipitation, and strong wind inside sampler housings, it is likely that heterogeneous reactions with $\mathrm{O}_{3}$ will play an important role in degrading PACs associated with PUFs.

The objective of this study was to evaluate the stability of PACs associated with PUF disks upon $\mathrm{O}_{3}$ exposure. The studied PACs included a number of alkylated PACs whose reactivities toward $\mathrm{O}_{3}$ have been rarely reported. A flow tube reactor was used to simulate the air sampling conditions in which PUF disks were exposed to $\mathrm{O}_{3}$ at concentrations and durations that were approximately equivalent to exposing PUFs at ambient $\mathrm{O}_{3}$ concentrations $(\sim 50 \mathrm{ppb})$ for two months, the typical deployment period for these passive samplers. To our knowledge, this is the first laboratory study to evaluate stability of PACs in PUF-type passive air samplers. The outcomes of this study will be relevant not only for passive air sampling using PUF and other substrates but also for active air sampling studies in which PUFs, used for collecting gas phase compounds, are exposed to oxidants.

\section{Materials and methods}

\subsection{Chemicals and materials}

The monitored PAH, alkylated PAHs, and dibenzothiophene and its alkylated homologs are listed in Table 1. Standards for the parent PAHs were purchased from Cambridge Isotope Labs (Andover, MA) and Chiron (Trondheim, Norway). Deuterium-labeled PAHs and ${ }^{13} \mathrm{C}$-phenanthrene were purchased from Cambridge Isotope Labs (Andover, MA). The isotopically labeled recovery PAH surrogates included $\mathrm{d}_{12}$-2,6-dimethylnaphthalene, $\mathrm{d}_{10}$-acenaphthene, ${ }^{13} \mathrm{C}$ phenanthrene, $\mathrm{d}_{10}$-anthracene, $\mathrm{d}_{10}$-benzo(b)naphtho(2,1-D)-thiophene, $d_{12}$-chrysene, $d_{12}$-benzo(b)fluoranthene, $d_{12}$-benzo(e)pyrene, $d_{14}$-dibenz(a,h)anthracene, $d_{12}$-indeno(123-cd)pyrene. The labeled PAH internal standards included $\mathrm{d}_{10}$-fluorene and $\mathrm{d}_{12-}$ benz(a)anthracene. PUF disks (TE-1014, $14 \mathrm{~cm}$ diameter $\times 1.35 \mathrm{~cm}$ thick) were purchased from Tisch Environmental (Village of Cleves, $\mathrm{OH})$.

\section{2. $\mathrm{O}_{3}$ exposures}

PUFs were pre-cleaned before use using a previously published protocol. (Schuster et al., 2015) A pipet was used to distribute $320 \mathrm{ng}$ of the individual PACs in $0.5 \mathrm{ml}$ of isooctane evenly onto a cleaned PUF disk. The spiked PUFs were air-dried in a fume hood for 5 min to allow solvent to evaporate before being placed in the flow tube chamber. An illustration of the experimental setup for the flow tube chamber is shown in Fig. 1. The flow tube was of electropolished stainless steel with an inner diameter of $19.8 \mathrm{~cm}$ and length of $255 \mathrm{~cm}$. The setup consisted of three air streams delivered into the flow tube: (1) $\mathrm{O}_{3}$ generated by a TG-10 Ozone Generator (Ozone Solutions, IA), (2) zero air for dilution generated by a zero air source (AADCO Model 737), and (3) humid air generated by passing zero air through a gas-washing bottle filled with deionized water. $\mathrm{O}_{3}$ concentrations were monitored by an Ozone analyzer (Model 205, 2B Technologies, CO). A probe was used to measure relative humidity $(\mathrm{RH})$ of the mixture in the flow tube chamber. The PUFs were exposed for $\sim 4.5 \mathrm{~h}$ with the average $\mathrm{O}_{3}$ concentrations at $\sim 40 \mathrm{ppm}$ (total flow of $11 \mathrm{LPM}$ ) and $14 \mathrm{ppm}$ (total flow of 4 LPM) at $0 \% \mathrm{RH}$ and $50 \% \mathrm{RH}$ respectively. The experiments at $0 \% \mathrm{RH}$ and $50 \%$ $\mathrm{RH}$ were conducted in triplicate. In both cases, total $\mathrm{O}_{3}$ concentrations were approximately equivalent to exposing the PUFs to an ambient $\mathrm{O}_{3}$ concentration of $\sim 50 \mathrm{ppb}$ for two months. A clean blank filter was also placed in the flow tube and exposed to $\mathrm{O}_{3}$ for $\sim 4.5 \mathrm{~h}$ to test for background contamination. The result showed that there was no significant PAC contamination in the flow tube system or the laboratory.

Losses of PACs from PUF disks in the flow tube system could be caused by reaction with $\mathrm{O}_{3}$ and evaporation. Control experiments at $0 \% \mathrm{RH}$ and $50 \% \mathrm{RH}$ were carried out in triplicate by passing a stream of zero air across PUFs spiked with the PACs in the chamber to determine losses from evaporation, in the absence of $\mathrm{O}_{3}$, occurring inside the flow tube chamber over the course of exposure.

\subsection{Sample preparation and analysis}

Samples were prepared and analyzed using methods described previously. (Schuster et al., 2015) Briefly, PUFs were spiked with the labeled recovery PAH surrogates and extracted with pressurized liquid extraction using petroleum ether and acetone (75:25, v:v; 2 cycles). The extracts were evaporated under a purified $\mathrm{N}_{2}$ stream with a Turbovap II (Biotage, NC). Sample extracts were spiked with the labeled PAH internal standards and were analyzed using gas chromatography mass spectrometry (Agilent 6890 coupled with an Agilent 5975 MSD), in electron impact in selected ion monitoring mode, on a DB-XLB column (30 m $\times 0.25 \mathrm{~mm}$ I.D., $0.25 \mu \mathrm{m}$ film thickness, Agilent Technologies).

\section{Results and discussion}

Percent recoveries of the PACs from the control experiments averaged $100 \%$ (ranging from $54 \%$ to $144 \%$ ) and $104 \%$ (59\%-153\%) 
Table 1

List of target analytes and their abbreviations.

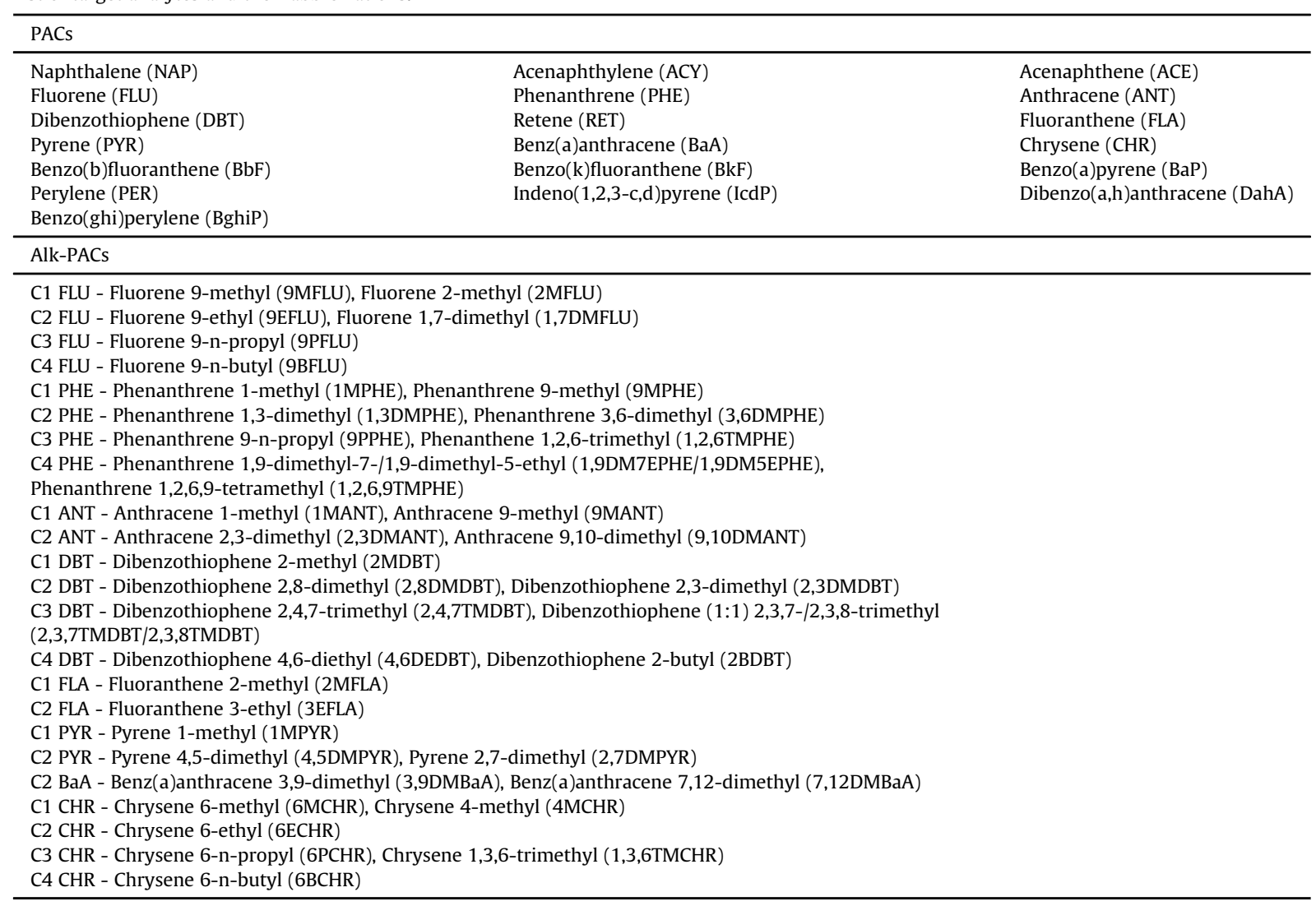

for the $0 \% \mathrm{RH}$ and $50 \% \mathrm{RH}$ experiments, respectively (Figure SI.1, Tables SI.1 and SI.2, Supporting Information). In both cases, the lowest recoveries were attributed to naphthalene (NAP) which exists primarily in the gas phase. Higher percent recoveries of other volatile and semi-volatile PACs containing 3-4 rings (mean of $105 \%$ and $111 \%$ at $0 \% \mathrm{RH}$ and $50 \% \mathrm{RH}$, respectively) indicated that the PUF disks have a high sorptive capacity and are able to retain the majority of the compounds that have significant fractions in the gas phase. Excluding NAP, average percent recoveries were $101 \%$ and $105 \%$ at $0 \% \mathrm{RH}$ and $50 \% \mathrm{RH}$, respectively, suggesting that volatilization of these compounds from PUFs was minimal during the course of the experiment.
To correct for the evaporation losses for compounds with higher volatilization, the amount of individual PAC degraded after exposure to $\mathrm{O}_{3}$ was calculated by dividing the average masses in the exposed samples by those in the control samples. Fig. $2 \mathrm{~A}$ and $\mathrm{B}$ shows the $\mathrm{PAC}_{\text {exposed }} / \mathrm{PAC}_{\text {unexposed }}$ ratios for the exposures at $0 \% \mathrm{RH}$ and 50\% RH, respectively. The means and standard deviations of PAC masses are given in Tables SI.1 and SI.2, Supporting Information. An asterisk indicates a statistically significant difference in mass after exposure to $\mathrm{O}_{3}$, as compared to the control ( $p$ value $<0.05$, student's t-test). A filled dot denotes a statistically significant difference between the exposed masses at $0 \% \mathrm{RH}$ and $50 \% \mathrm{RH}$ ( $p$-value $<0.05$, student's t-test). At $0 \% \mathrm{RH}$, the mean

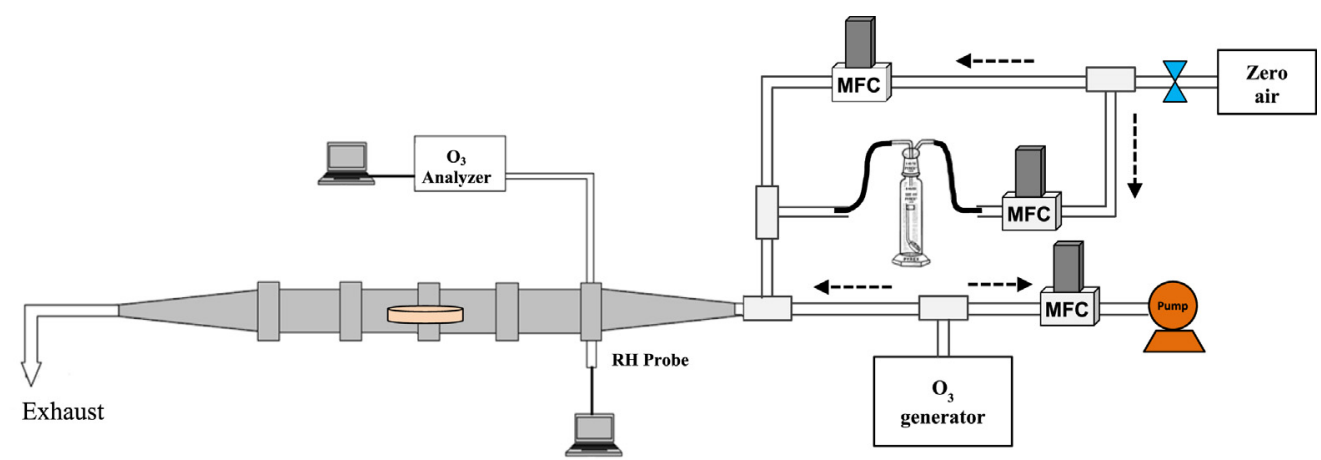

$\rightleftarrows$ PUF spiked with PACs

Mass flow controller

Fig. 1. Experimental setup for the flow tube chamber. 

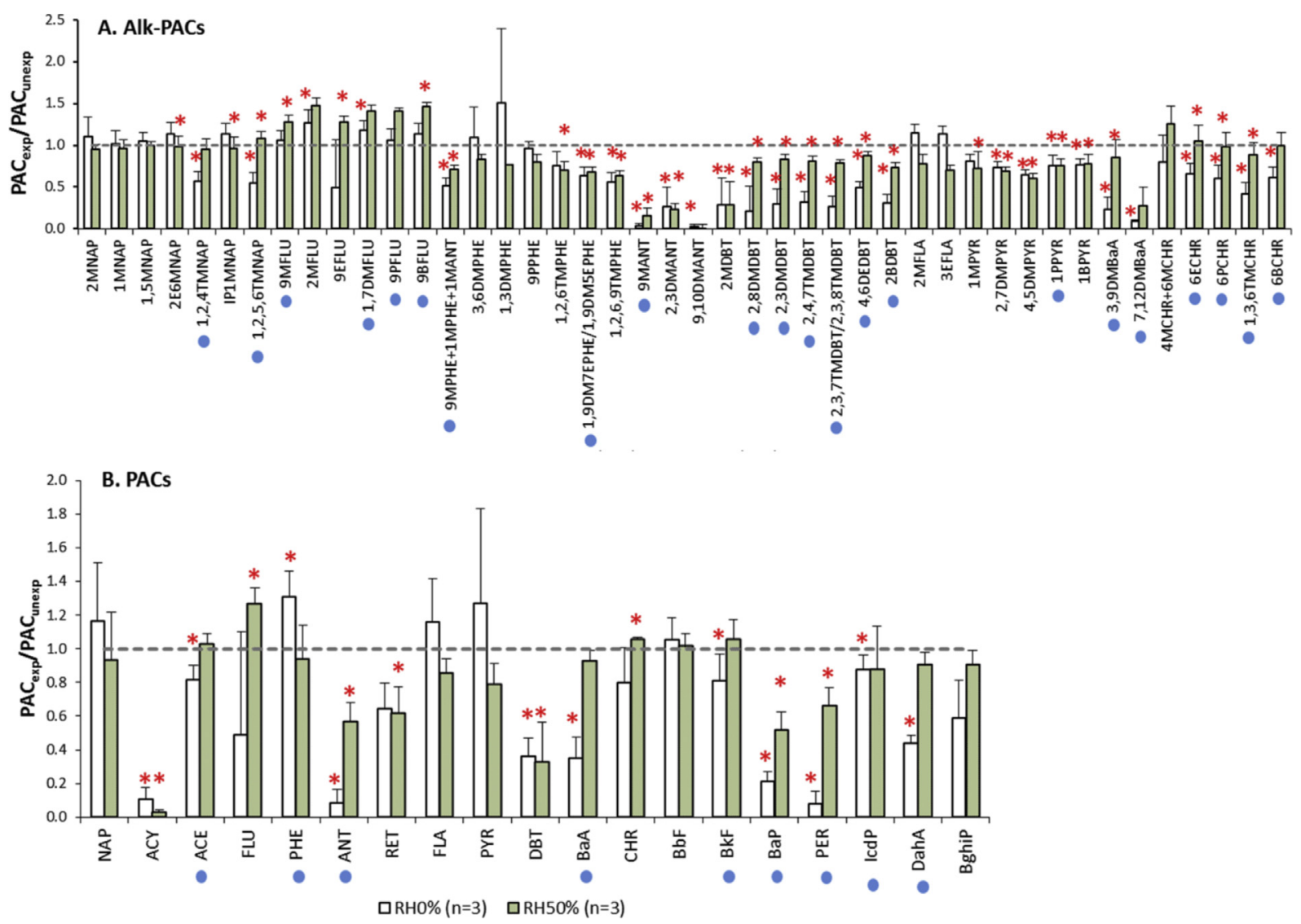

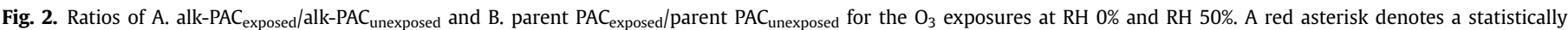

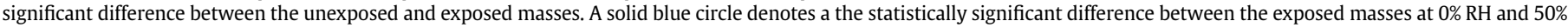
RH. See Table 1 for chemical names. (For interpretation of the references to color in this figure legend, the reader is referred to the web version of this article.)

$\mathrm{PAC}_{\text {exposed }} / \mathrm{PAC}_{\text {unexposed }}$ ratios were 0.66 and 0.70 for the parent PAHs and alk-PACs, respectively (Fig. 2A and Table SI.1, Supporting Information). The most reactive parent PAHs and alk-PACs were (see Table 1 for compound names) PER and 9,10DMANT, respectively. Fifteen alk-PACs (C2-FLU, C1-ANT, C2-ANT, alk-DBTs, and C2$\mathrm{BaA}$ ) and eight parent PAHs (including ACY, FLU, ANT, DBT, BaA, BaP, PER, DahA) exhibited significant losses ( $>50 \%$ ) after the $\mathrm{O}_{3}$ exposure at $0 \% \mathrm{RH}$.

At $50 \% \mathrm{RH}$, the mean $\mathrm{PAC}_{\text {exposed }} / \mathrm{PAC}_{\text {unexposed }}$ ratios were 0.81 and 0.85 for the parent PAHs and alk-PACs, respectively (Fig. 2B and Table SI.1, Supporting Information). The most reactive parent PAHs and alk-PACs were ACY and 9,10DMANT, respectively. Significant losses (>50\%) were found for ACY, 9MANT, 2,3DMAN, 9,10DMANT, DBT, 2MDBT, and 7,12DMBaA. The reactivity of higher ring PAHs (BaA, BaP, PER, DahA) that resulted in significant losses at $0 \% \mathrm{RH}$ decreased at 50\% $\mathrm{RH}$. Despite the decrease in reactivity at 50\% $\mathrm{RH}$, $48 \%$ of BaP mass reacted after the exposure. Except for PHE and IcdP, for the case where PAC masses were statistically different ( $p$ value $<0.05$ ) between the $0 \% \mathrm{RH}$ and $50 \% \mathrm{RH}$, the ratios of $\mathrm{PAC}_{\mathrm{e}-}$ xposed $/ \mathrm{PAC}_{\text {unexposed }}$ at $50 \% \mathrm{RH}$ were higher than those at $0 \% \mathrm{RH}$. This implies that water vapor played a significant role in stabilizing the PACs in PUFs. The observed humidity dependence is consistent with previous studies which attributed the decreases in PAC reactivity to the competitive adsorption of water vapor and $\mathrm{O}_{3}$ on surfaces which could interfere with the heterogeneous reactions of PACs with $\mathrm{O}_{3}$. (Pitts et al., 1986; Pöschl et al., 2001) It is also possible that water condensed in the pores of the PUF could have slowed down the diffusion of $\mathrm{O}_{3}$. However, the $\mathrm{O}_{3}$ degradation of the reactive PACs, including ACY and DBT, 2,3DMAN, 9,10DMANT,
2MDBT, was less dependent on RH. We note that in a few instances $\mathrm{PAC}_{\exp } / \mathrm{PAC}_{\text {unexp }}$ values exceeded 1.0 (Fig. 2) which could be attributed to experimental and analytical variability as shown in Figure SI.1.

Overall, this study demonstrates that the majority of PACs $(77 \%$ of the studied PACs), under the simulated conditions, were stable $\left(\mathrm{PAC}_{\text {exposed }} / \mathrm{PAC}_{\text {unexposed }}>0.7\right)$ upon $\mathrm{O}_{3}$ exposure at $50 \% \mathrm{RH}$. However, significant chemical losses of some volatile PACs were observed at $50 \% \mathrm{RH}$. The degree of degradation by $\mathrm{O}_{3}$ in PUFs varies depending on the molecular structure and humidity. There was no distinguishable relationship between reactivity and degree of alkylation. For the reactive PACs, the results could lead to an underestimation of air concentrations which may have important implications for compounds that are used in air quality guidelines, such as BaP. As such, the underestimation of PAC concentrations in air can also be expected from active air sampling where $\mathrm{O}_{3}$ and gasphase compounds are drawn through PUF plugs, when a denuder is not installed, allowing PAC transformation.

It is important to note that the observed degradation in this study represents the upper limit or worst case scenario as PUFs were openly exposed to oxidants and chemicals that were applied onto the PUF disks were not bound to particles. In the real environment, PACs with more than 4 rings, including reactive BaP, PER, and DahA, are mainly associated with particulate matter (Su et al., 2006; Yamasaki et al., 1982) and hence suffer from $\mathrm{O}_{3}$ degradation to a lesser extent as they are partially shielded from gaseous oxidants by black carbon, organic matter, and the accumulation of atmospheric reaction products on the surface. (Jariyasopit et al., 2014; Lammel et al., 2009; Zhou et al., 2012) Furthermore, it is 
also likely that in ambient air, the fraction of the reactive PACs on freshly emitted particles that are available for chemical reactions would have already partially reacted in the atmosphere prior to collection. (Jariyasopit et al., 2014) These particle-bound PACs will become less available for further degradation as particles are photochemically aged. Additionally, as shown in previous studies (Pitts et al., 1986; Pöschl et al., 2001) and this study, humidity can potentially promote the stability of the PACs by suppressing $\mathrm{O}_{3}$ reactions. For instance, under the conditions in the Athabasca oil sands region where the relative humidity annual mean was $67 \%$, (Jung et al., 2011) it is expected that most of the PACs accumulated on PUF disks will be stable toward $\mathrm{O}_{3}$ degradation during the twomonth sampling collection period.

\section{Conclusions}

In summary, the results show that the passive PUF disk samplers are capable of accurately reflecting PAC concentrations in air; however, the reactive PAC (acenaphthylene, 2,3dimethylanthracene, 9,10-dimethylanthracene, dibenzothiophene, and 2-methyldibenzothiophene) concentrations should be interpreted with caution. Although it has been shown that $\mathrm{O}_{3}$ was an effective oxidant for heterogeneous reactions of particle-bound PACs (Jariyasopit et al., 2014), it should also be noted that in a real world environment the coexistence of $\mathrm{O}_{3}$ and other atmospheric oxidants (e.g. OH radicals, $\mathrm{NO}_{3}$ radicals, $\mathrm{NO}_{2}, \mathrm{~N}_{2} \mathrm{O}_{5}$ ) could complicate the degradation reactions of the PACs associated with PUF disks. Moreover, the experiments are based on the assumption that the kinetics of heterogeneous reactions are linear with $\mathrm{O}_{3}$ concentration. Deviation from linearity may be possible under ambient conditions. In the future, it would be useful to conduct similar studies to assess the stability of other priority chemicals frequently collected using PUF disk samplers and to consider different oxidant types under varying concentrations and exposure times.

\section{Acknowledgments}

This work was partially funded by the Chemicals Management Plan and the Clean Air Regulatory Agenda.

\section{Appendix A. Supplementary data}

Supplementary data related to this article can be found at http:// dx.doi.org/10.1016/j.atmosenv.2015.08.088.

\section{References}

Baird, W.M., Hooven, L.A., Mahadevan, B., 2005. Carcinogenic polycyclic aromatic hydrocarbon-DNA adducts and mechanism of action. Environ. Mol. Mutagen. 45, 106-114.

Bartkow, M.E., Huckins, J.N., Müller, J.F., 2004. Field-based evaluation of semipermeable membrane devices (SPMDs) as passive air samplers of polyaromatic hydrocarbons (PAHs). Atmos. Environ. 38, 5983-5990.

Bartkow, M.E., Kennedy, K.E., Huckins, J.N., Holling, N., Komarova, T., Müller, J.F., 2006. Photodegradation of polyaromatic hydrocarbons in passive air samplers: field testing different deployment chambers. Environ. Pollut. 144, 371-376.

Bedjanian, Y., Nguyen, M.L., 2010. Kinetics of the reactions of soot surface-bound polycyclic aromatic hydrocarbons with $\mathrm{O}_{3}$. Chemosphere 79, 387-393.

Esteve, W., Budzinski, H., Villenave, E., 2004. Relative rate constants for the heterogeneous reactions of $\mathrm{OH}, \mathrm{NO}_{2}$ and $\mathrm{NO}$ radicals with polycyclic aromatic hydrocarbons adsorbed on carbonaceous particles. Part 1: PAHs adsorbed on 1$2 \mu \mathrm{m}$ calibrated graphite particles. Atmos. Environ. 38, 6063-6072.

Goriaux, M., Jourdain, B., Temime, B., Besombes, J.-L., Marchand, N., Albinet, A., Leoz-Garziandia, E., Wortham, H., 2006. Field comparison of particulate $\mathrm{PAH}$ measurements using a low-flow denuder device and conventional sampling systems. Environ. Sci. Technol. 40, 6398-6404.

Harner, T., Bartkow, M., Holoubek, I., Klanova, J., Wania, F., Gioia, R., Moeckel, C., Sweetman, A.J., Jones, K.C., 2006. Passive air sampling for persistent organic pollutants: introductory remarks to the special issue. Environ. Pollut. 144, $361-364$.

Hawthorne, S.B., Miller, D.J., Kreitinger, J.P., 2006. Measurement of total polycyclic aromatic hydrocarbon concentrations in sediments and toxic units used for estimating risk to benthic invertebrates at manufactured gas plant sites. Environ. Toxicol. Chem. 25, 287-296.

Jariyasopit, N., Zimmermann, K., Schrlau, J., Arey, J., Atkinson, R., Yu, T.-W., Dashwood, R.H., Tao, S., Simonich, S.L.M., 2014. Heterogeneous reactions of particulate matter-bound PAHs and NPAHs with $\mathrm{NO}_{3} / \mathrm{N}_{2} \mathrm{O}_{5}, \mathrm{OH}$ radicals, and $\mathrm{O}_{3}$ under simulated long-range atmospheric transport conditions: reactivity and mutagenicity. Environ. Sci. Technol. 48, 10155-10164.

Jaward, F.M., Farrar, N.J., Harner, T., Sweetman, A.J., Jones, K.C., 2004. Passive air sampling of PCBs, PBDEs, and organochlorine pesticides across Europe. Environ. Sci. Technol. 38, 34-41.

Jung, K., Ok, Y.S., Chang, S.X., 2011. Sulfate adsorption properties of acid-sensitive soils in the Athabasca oil sands region in Alberta, Canada. Chemosphere 84, 457-463.

Klánová, J., Kohoutek, J., Hamplová, L., Urbanová, P., Holoubek, I., 2006. Passive air sampler as a tool for long-term air pollution monitoring: part 1. Performance assessment for seasonal and spatial variations. Environ. Pollut. 144, 393-405.

Lammel, G., Sehili, A.M., Bond, T.C., Feichter, J., Grassl, H., 2009. Gas/particle partitioning and global distribution of polycyclic aromatic hydrocarbons - a modelling approach. Chemosphere 76, 98-106.

Motelay-Massei, A., Harner, T., Shoeib, M., Diamond, M., Stern, G., Rosenberg, B., 2005. Using passive air samplers to assess urban-rural trends for persistent organic pollutants and polycyclic aromatic hydrocarbons. 2. Seasonal trends for PAHs, PCBs, and organochlorine pesticides. Environ. Sci. Technol. 39, 5763-5773.

Nguyen, M., Bedjanian, Y., Guilloteau, A., 2009. Kinetics of the reactions of soot surface-bound polycyclic aromatic hydrocarbons with $\mathrm{NO}_{2}$. J. Atmos. Chem. 62, $139-150$.

Perraudin, E., Budzinski, H., Villenave, E., 2007. Kinetic study of the reactions of ozone with polycyclic aromatic hydrocarbons adsorbed on atmospheric model particles. J. Atmos. Chem. 56, 57-82.

Pitts, J.N., Paur, H.-R., Zielinska, B., Arey, J., Winer, A.M., Ramdahl, T., Mejia, V., 1986. Factors influencing the reactivity of polycyclic aromatic hydrocarbons adsorbed on filters and ambient POM with ozone. Chemosphere 15, 675-685.

Pöschl, U., Letzel, T., Schauer, C., Niessner, R., 2001. Interaction of ozone and water vapor with spark discharge soot aerosol particles coated with benzo[a]pyrene: $\mathrm{O}_{3}$ and $\mathrm{H}_{2} \mathrm{O}$ adsorption, benzo[a]pyrene degradation, and atmospheric implications. J. Phys. Chem. A 105, 4029-4041.

Pozo, K., Harner, T., Shoeib, M., Urrutia, R., Barra, R., Parra, O., Focardi, S., 2004. Passive-sampler derived air concentrations of persistent organic pollutants on a North-South transect in Chile. Environ. Sci. Technol. 38, 6529-6537.

Ringuet, J., Albinet, A., Leoz-Garziandia, E., Budzinski, H., Villenave, E., 2012. Reactivity of polycyclic aromatic compounds (PAHs, NPAHs and OPAHs) adsorbed on natural aerosol particles exposed to atmospheric oxidants. Atmos. Environ. 61, 15-22.

Schauer, C., Niessner, R., Pöschl, U., 2003. Polycyclic aromatic hydrocarbons in urban air particulate matter: decadal and seasonal trends, chemical degradation, and sampling artifacts. Environ. Sci. Technol. 37, 2861-2868.

Schuster, J.K., Harner, T., Su, K., Mihele, C., Eng, A., 2015. First results from the oil sands passive air monitoring network for polycyclic aromatic compounds. Environ. Sci. Technol. 49, 2991-2998.

Su, Y., Lei, Y.D., Wania, F., Shoeib, M., Harner, T., 2006. Regressing Gas/Particle partitioning data for polycyclic aromatic hydrocarbons. Environ. Sci. Technol. 40, 3558-3564.

Yamasaki, H., Kuwata, K., Miyamoto, H., 1982. Effects of ambient temperature on aspects of airborne polycyclic aromatic hydrocarbons. Environ. Sci. Technol. 16, 189-194.

Yang, C., Wang, Z., Yang, Z., Hollebone, B., Brown, C.E., Landriault, M., Fieldhouse, B., 2011. Chemical fingerprints of Alberta oil sands and related petroleum products. Environ. Forensics 12, 173-188.

Zhou, S., Lee, A., McWhinney, R., Abbatt, J., 2012. Burial effects of organic coatings on the heterogeneous reactivity of particle-borne benzo[a]pyrene (BaP) toward ozone. J. Phys. Chem. A 116, 7050-7056. 